\title{
Malignant conjunctival T cell lymphoma diagnosed by punch biopsy as a primary manifestation of systemic cancer
}

This article was published in the following Dove Press journal:

Clinical Ophthalmology

19 May 2012

Number of times this article has been viewed

\section{Vincenzo Isola' \\ Danilo Mazzacane' \\ Noemi Defelice' \\ Antonio D'Amico' \\ Laura Dezza ${ }^{2}$ \\ Antonio Marti ${ }^{3}$ \\ Alfredo Pece ${ }^{1,4}$}

'Department of Ophthalmology, Melegnano Hospital, ${ }^{2}$ Oncology

Service, ${ }^{3}$ Department of Radiology,

${ }^{4}$ Fondazione Retina 3000, Milan, Italy

\begin{abstract}
This report documents a case of $\mathrm{T}$ cell lymphoma manifesting only with a conjunctival mass. A 67-year-old man underwent a diagnostic punch biopsy, histopathological examination, and immunohistochemical study for a pink-yellow colored mass infiltrating the bulbar conjunctiva in the lower fornix of the eyelid. A biopsy specimen of the conjunctival mass was found histopathologically to be a malignant $\mathrm{T}$ cell lymphoma. Systemic involvement was diagnosed within four weeks after the initial diagnosis by computed tomography, showing evidence of extension at the level of the ethmoidal cells, optic nerve, periorbital tissue, and pancreas. T cell lymphoma of the conjunctiva as a primary manifestation of systemic cancer is an uncommon entity. Punch biopsy may be the first diagnostic pathway useful to initiate a search for systemic involvement of a malignant lymphoid tumor of T cell lineage.
\end{abstract}

Keywords: conjunctiva, cancer, T cell lymphoma, biopsy

\section{Introduction}

Lymphoid neoplasms of the conjunctiva may appear as an isolated tumor or as part of systemic disease. ${ }^{1-5}$ Generally, conjunctival lymphoma presents as a mass lesion on the superficial ocular surface. These lymphomas are classically described as "salmon-colored patches", and may present bilaterally in up to $20 \%$ of patients. ${ }^{4,5}$ Lesions have a fleshy appearance and may develop rapidly. Often they appear to arise from within the fornix and extend towards the cornea. B cell lymphoma is the most common type of conjunctival lymphoma, whereas the $\mathrm{T}$ cell form is very rare..$^{2-5}$ In this report, we document the clinical and histopathological findings in a patient with conjunctival lymphoma that was the first presentation of systemic malignant lymphomatous $\mathrm{T}$ cell proliferation.

\section{Case report}

On March 15, 2006, a 67-year-old male patient came to our attention complaining of pain and hyperemia in his left eye. His medical history was significant for weight loss in the last previous two months. His visual acuity was 20/80 in both eyes. Anterior segment slit-lamp biomicroscopy of the left eye showed a pink-yellow colored mass infiltrating the bulbar conjunctiva in the lower fornix of the eyelid and a corneal ulcer at the $9 \mathrm{o}$ 'clock position with perilimbal congestion and chemosis (Figure 1A and B). Funduscopy was normal. The right eye did not show any abnormality. The left eye was treated with topical steroid/antibiotic medication with an ocular bandage for one week.

A control visit showed disappearance of corneal ulcer, and a diagnostic punch biopsy of the conjunctival mass was taken for immunohistochemical examination.
Correspondence: Vincenzo Isola Department of Ophthalmology, Melegnano Hospital, Via Pandina I, 20077 Vizzolo Predabissi, Milano, Italy

Tel +39298052267

Fax +39298052267

Email vincenzo.isola@gmail.com 

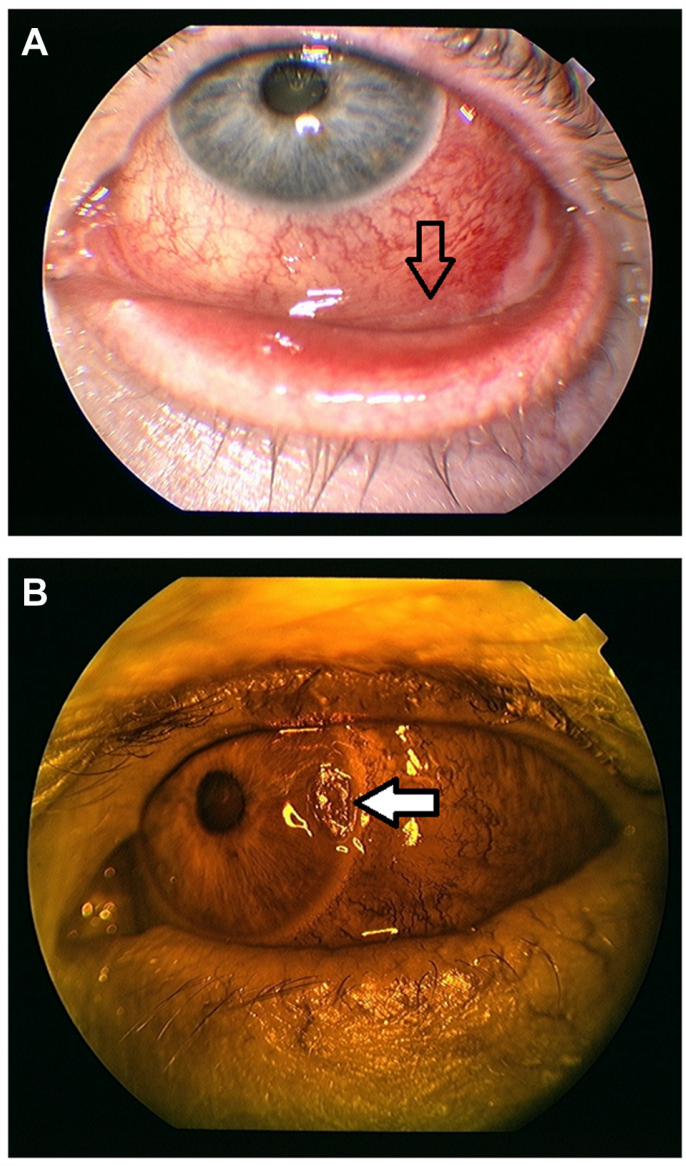

Figure I (A and B) Anterior segment slit-lamp photograph of the left eye showing a pink-yellow colored mass infiltrating the bulbar conjunctiva in the lower fornix of the eyelid (arrow) and a corneal ulcer at the 9 o'clock position with perilimbal congestion and chemosis (arrow).

The conjunctiva was infiltrated by a diffuse proliferation of small- to medium-sized lymphoid cells which were partly necrotic. The lymphoid population showed nuclear atypia, vesicular nuclei, and prominent nucleoli. Focal effacement of the serous glands of the conjunctiva was observed (Figure 2). The neoplastic cells were homogeneously CD3+,

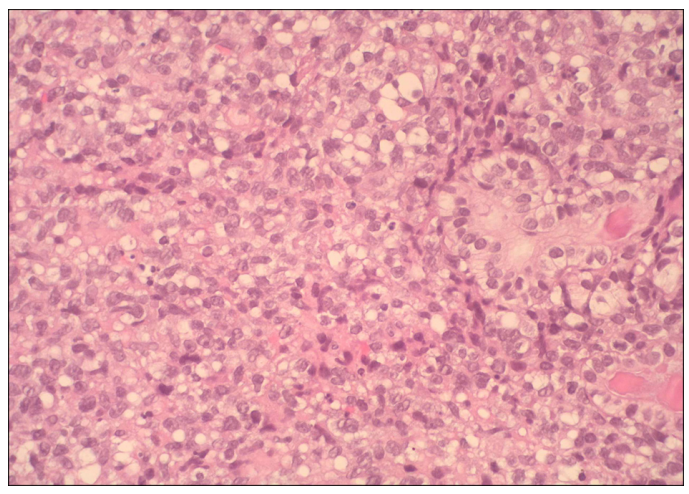

Figure 2 Diffuse proliferation of small atypical lymphoid cells, partly effacing the mucosal glands (hematoxylin and eosin, 40x).
CD5-, CD20-, and CD43(MT1)+/-. A high proliferation rate reaching $80 \%$ of the neoplastic population was observed, as detected by Ki67/MIB1 immunoreactivity (Figure 3A and B). Over the next two weeks, the patient had ptosis and exophthalmos in the right eye. Slit-lamp biomicroscopy revealed
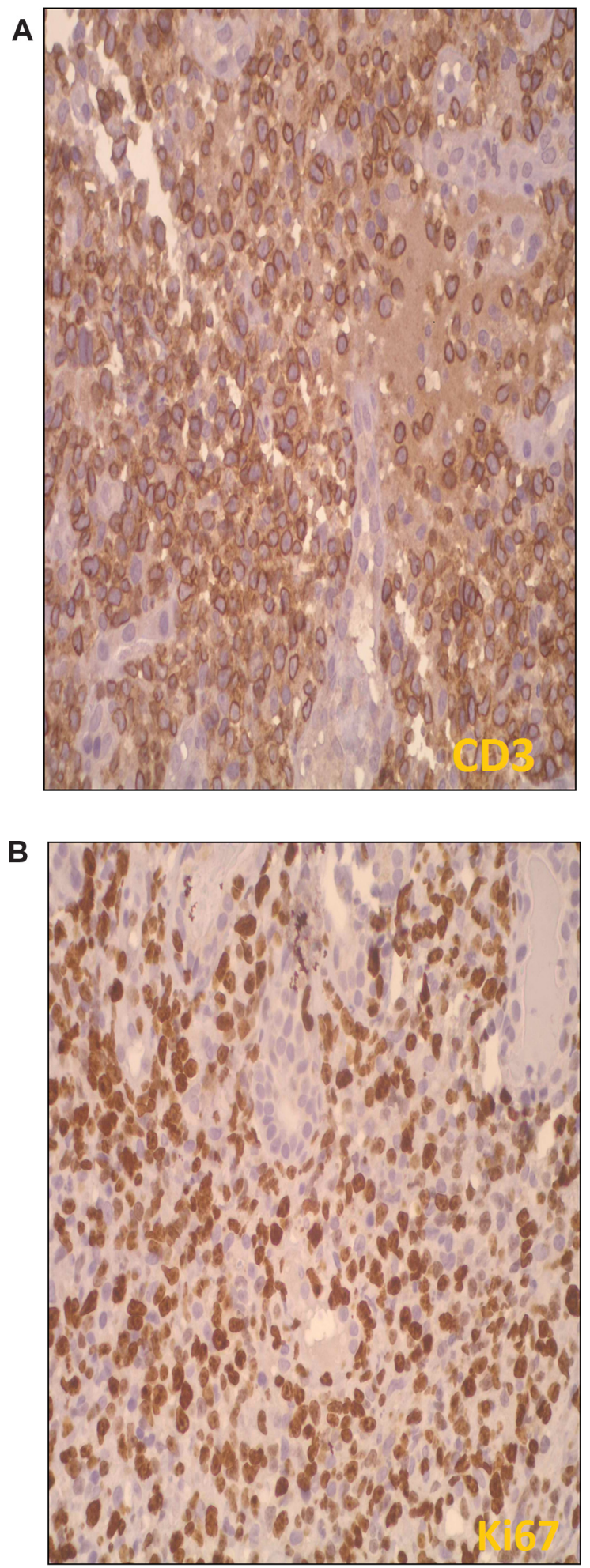

Figure 3 (A and B) CD3 and Ki67 immunoreactivity (ABC peroxidase, 40×). 

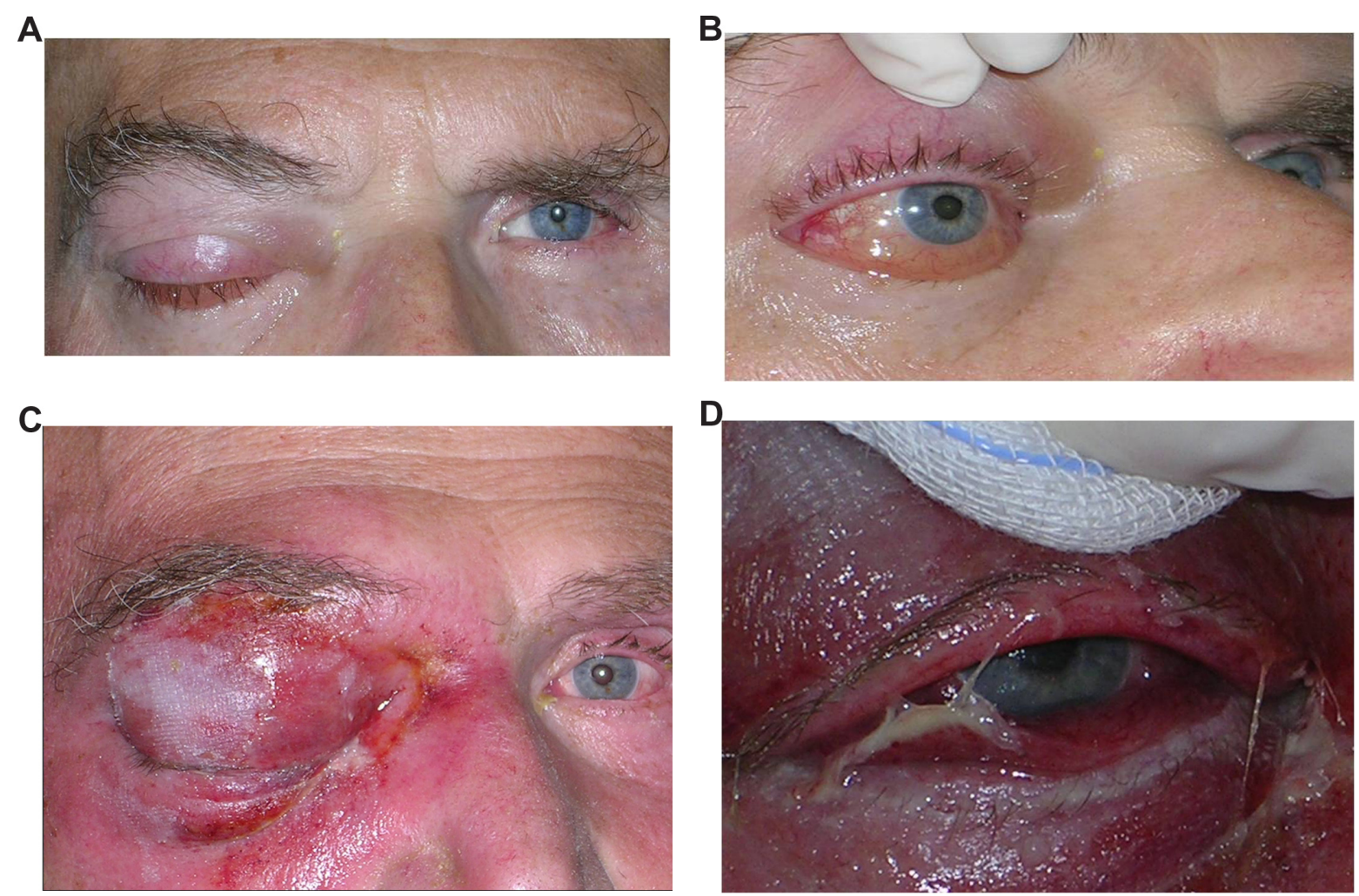

Figure 4 (A and B) Photographic documentation of ptosis and conjunctival chemosis involving the right eye. (C and D) Massive extension at the right ocular adnexa with ptosis, proptosis, and periorbital tissue infiltration.

diffuse congestion and marked chemosis involving the entire epibulbar conjunctiva of the right eye (Figure 4A and B). Over a period of four weeks, there was rapid expansion of the tumor involving the right ocular adnexa, with ptosis, proptosis, and periorbital tissue infiltration (Figure 4C and D). Computed tomography of the maxillofacial region and abdomen demonstrated parenchymal infiltrations in the ethmoidal cells, periorbital region, and pancreas (Figure 5). The patient was followed carefully by the oncology service for staging that was classified as IVB. He was receiving a regimen of chemotherapy comprising cyclophosphamide $750 \mathrm{mg} / \mathrm{mq}$, epidoxorubicin $50 \mathrm{mg} / \mathrm{mq}$, vincristine $1.4 \mathrm{mg} / \mathrm{mq}$, and prednisone $50 \mathrm{mg} / \mathrm{mq}$ on days 1 and 5 . Simultaneously, the patient underwent locoregional radiotherapy with a total of $20 \mathrm{~Gy}$ to the retro-orbital region. The patient died of an acute myocardial infarction after the two cycles of chemotherapy.
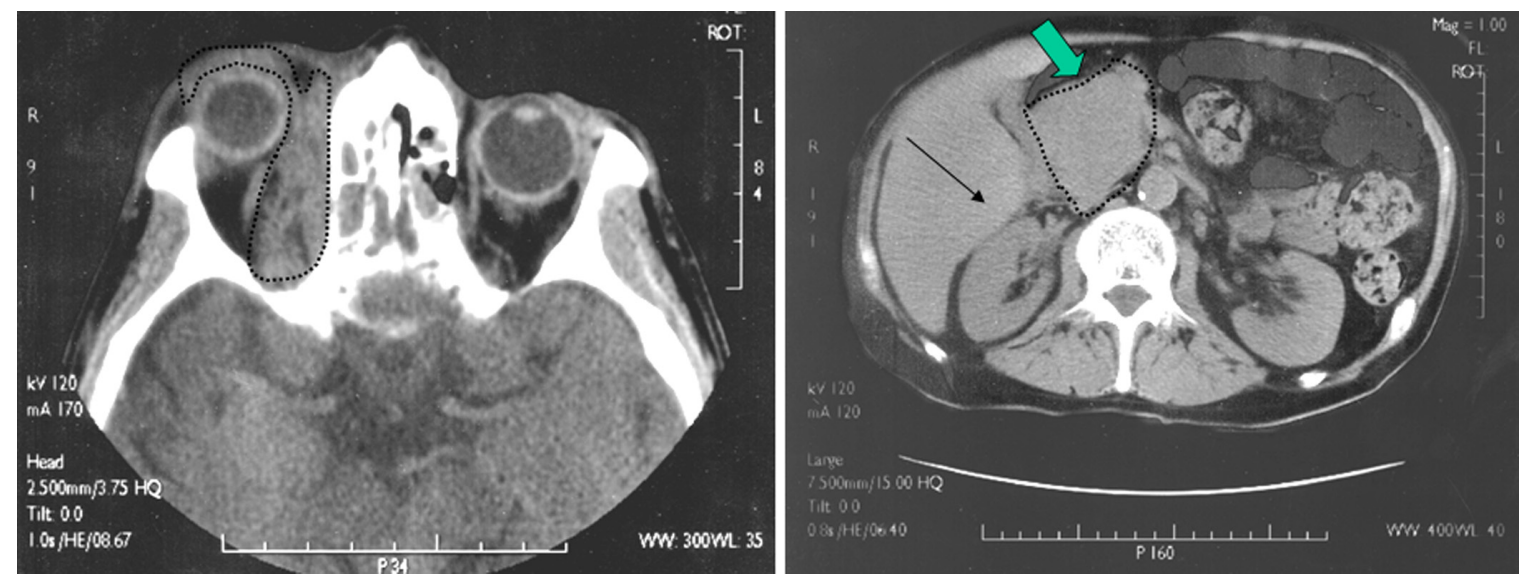

Figure 5 Computed tomography of the maxillofacial region showing parenchymatous infiltrations at the level of the ethmoidal cells, optic nerve, and the medial and anterior periorbital region (dotted line).

Note: Abdominal computed tomography demonstrated a lymphoid mass at the level of the head and body of the pancreas (arrows). 


\section{Discussion}

Ocular involvement of T cell lymphoma may include orbital, conjunctival, eyelid, uveal, and vitreous localization. ${ }^{1}$ Malignant ocular T cell lymphoma can be associated with systemic involvement. ${ }^{2-5}$ Despite a typical appearance, the differential diagnosis includes scleritis and several other benign tumors of the ocular surface, including squamous papilloma, pyogenic granuloma, and lymphangiectasis. ${ }^{4}$

There are two important aspects concerning this case report. Firstly, the initial manifestation of this tumor was at the lower fornix of the left conjunctiva that was easy accessible to diagnostic punch biopsy, which enabled early diagnosis of $\mathrm{T}$ cell lymphoma. Secondly, general examination showed systemic involvement with ethmoidal, maxillary and sphenoidal sinus masses, and pancreatic infiltration. An orbital component was also evident. Lymphoid tumors of the conjunctiva are associated with systemic lymphoma in about $31 \%$ of patients. ${ }^{4}$ They may not be symptomatic for many months or years. ${ }^{1-5}$ In this case, we could not identify the primary site of the lymphoid tumor because ocular involvement was found to be associated with extraocular systemic lymphomatous proliferation. T cell lymphoma of the conjunctiva as a primary manifestation of systemic cancer is an extremely rare entity. Punch conjunctival biopsy may be the first diagnostic pathway useful to initiate a search for systemic involvement of a malignant lymphoid tumor of the T cell variety.

\section{Disclosure}

The authors report no conflicts of interest in this work.

\section{References}

1. Hu FR, Lin JC, Chiang IP, Yeh KH. T-cell malignant lymphoma with conjunctival involvement. Am J Ophthalmol. 1998;125(5):717-719.

2. Al-Muammar A, Hodge WG, Farmer J. Conjunctival T-cell lymphoma: a clinicopathologic case report. Ophthalmology. 2006;113(3): 459-461.

3. Shields CL, Shields JA, Eagle RC. Clinicopathologic reports, case reports, and small cases series: rapidly progressive T-cell lymphoma of the conjunctiva. Arch Ophthalmol. 2002;120(4):508-509.

4. Shields CL, Shields JA, Carvalho C, et al. Conjunctival lymphoid tumors: clinical analysis of 117 cases and relationship to systemic lymphoma. Ophthalmology. 2001;108(5):979-984.

5. Kirn TJ, Levy NB, Gosselin JJ, Rosen WJ, Zegans ME. Peripheral T-cell lymphoma presenting as sclerouveitis. Cornea. 2007;26(9): $1147-1149$.
Clinical Ophthalmology

\section{Publish your work in this journal}

Clinical Ophthalmology is an international, peer-reviewed journal covering all subspecialties within ophthalmology. Key topics include: Optometry; Visual science; Pharmacology and drug therapy in eye diseases; Basic Sciences; Primary and Secondary eye care; Patient Safety and Quality of Care Improvements. This journal is indexed on

Submit your manuscript here: http://www.dovepress.com/clinical-ophthalmology-journal

\section{Dovepress}

PubMed Central and CAS, and is the official journal of The Society of Clinical Ophthalmology (SCO). The manuscript management system is completely online and includes a very quick and fair peer-review system, which is all easy to use. Visit http://www.dovepress.com/ testimonials.php to read real quotes from published authors. 